\title{
Bouncing back from extreme weather events: some preliminary findings on resilience barriers facing small and medium-sized enterprises
}

Article

Accepted Version

Halkos, G., Skouloudis, A., Malesios, C. and Evangelinos, K. (2018) Bouncing back from extreme weather events: some preliminary findings on resilience barriers facing small and medium-sized enterprises. Business Strategy and the Environment, 27 (4). pp. 547-559. ISSN 0964-4733 doi: https://doi.org/10.1002/bse.2019 Available at https://centaur.reading.ac.uk/75507/

It is advisable to refer to the publisher's version if you intend to cite from the work. See Guidance on citing.

To link to this article DOI: http://dx.doi.org/10.1002/bse.2019

Publisher: Wiley

All outputs in CentAUR are protected by Intellectual Property Rights law, including copyright law. Copyright and IPR is retained by the creators or other copyright holders. Terms and conditions for use of this material are defined in the End User Agreement. 


\section{www.reading.ac.uk/centaur}

\section{CentAUR}

Central Archive at the University of Reading

Reading's research outputs online 


\title{
Bouncing back from extreme weather events: Some preliminary
}

\section{findings on resilience barriers facing Small and Medium-Sized Enterprises}

\author{
George Halkos ${ }^{1}$, Antonis Skouloudis ${ }^{2 *}$, Valantis Malesios ${ }^{3} \&$ Konstantinos Evangelinos $^{4}$ \\ ${ }^{1}$ Laboratory of Operations Research, University of Thessaly, Volos, 38333 \\ ${ }^{2}$ Henley Business School, University of Reading, Greenlands campus, Henley-on-Thames, RG9 3AU, UK \\ ${ }^{3}$ Department of Agricultural Development, Democritus University of Thrace, Orestiada, 68200 \\ ${ }^{4}$ Centre for Environmental Policy \& Strategic Env. Management, University of the Aegean, Lesvos, 81100 \\ * corresponding author
}

halkos@econ.uth.gr, a.skouloudis@henley.ac.uk, malesios@agro.duth.gr, kevag@aegean.gr

\begin{abstract}
Extreme Weather Events (EWEs) pose unprecedented threats to modern societies and represent a much-debated issue strongly interlinked with current development policies. Small and medium-sized enterprises (SMEs) that constitute a driving force of economic growth, employment and total value-added remain highly vulnerable to and ill-prepared for such environmental perturbations. This study investigates barriers to SMEs' resilience to EWEs in an attempt to shed light on enabling factors which can define effective organizational responses to nonlinear environmental stimuli. Relying on structural equation modeling and data gathered from 109 SMEs that recently experienced EWEs impacts, we link the general concept of SMEs' resilience barriers to EWEs with a series of elements to determine specific internal and external factors that contribute the most to EWE resilience. In particular, external barriers of institutional conditions and mechanisms of support and guidance as well as internal barriers of resources and managerial perceptions are found to be the most critical ones in determining resilience. The assessment offers essential research evidence for practitioners on SME management and sets forth linkages with current mechanisms for policy interventions towards an appropriate resilience agenda for SMEs.
\end{abstract}

Keywords: Extreme weather events; resilience; small and medium-sized enterprises; climate change; environmental perturbations; sustainable development 


\section{Introduction}

Scientific evidence suggests that climate change (CC) is expected to further affect the carrying capacity of ecosystems, generate large-scale environmental changes and increase the occurrence of extreme weather events - EWEs (IPCC, 2013; Munich Re, 2013; Stern, 2007). Owing to a massive scale as well as scope, irreversibility, destructiveness and high uncertainty, such impacts can be highly discontinuous (Gasbarro and Pinske, 2016). In Europe, recent years have witnessed severe heat waves, major floods, heavy precipitation and extreme storms (e.g. Dlugolecki, 2009; Poumadère et al., 2005) while the frequency and intensity of such impacts are projected to escalate (Forzieri et al., 2016).

Unexpected changes and disruptive events have always been a major challenge for business planning (Weick and Sutcliffe, 2001; Halkos and Skouloudis, 2016). However, very few environmental problems exhibit as much strategic challenges (and uncertainty) as that associated with CC and EWEs (Barnett, 2001; Whiteman et al., 2011; Gunawansa and Kua, 2014; Evangelinos et al., 2015; Amran et al., 2016; Gasbarro et al., 2016). Such environmental perturbations incur abrupt changes to business organizations in terms of asset damages, operational interruptions, increased costs as well as declining revenue and growth (Winn et al., 2011; Linnenluecke et al., 2011; 2012). It is therefore critical for businesses to identify such risks (Weinhofer and Busch, 2013), to reduce their vulnerability to EWE threats and, ultimately, to effectively build their resilience to climate-induced physical challenges (e.g. Tsalis and Nikolaou, 2017). Resilience indicates the ability to withstand, to adapt, and to quickly recover from stresses and shocks (European Commission, 2012). In this respect, organizational resilience signifies a blend of cognitive, behavioural, and contextual properties that allow a business entity to effectively absorb, develop situation-specific responses to, and ultimately engage in transformative activities to capitalize on disruptive surprises that potentially threaten its very survival (Lengnick-Hall et al., 2011). Fostering the resilience capacity of a firm enables it to overcome survival threats and actually secure its longevity and prosperity under a complicated, uncertain, and volatile environment (Sutcliffe and Vogus, 2003; Seville et al., 2008; Korhonen and Seager, 2008).

In its attempt to move towards higher levels of resilience to EWEs an enterprise may face an array of barriers. As such inhibitory factors are reduced, the firm will gain new skills, exploit new capabilities and achieve interventions or improvements towards 
better business continuity planning (Okereke et al. 2012). Likewise, when business entities experience extensive barriers to building resilience any intentions to foster disaster risk management will rarely be translated into actions. Such obstacles to managing environmental challenges can be either internal or external (Hillary, 2004; Chan, 2008; Shi et al., 2008). Barriers not pertaining within the firm (i.e. external barriers) refer to parameters which are out of the direct control or influence of the organization. Internal barriers are on the other hand dependent upon parameters that may be directly controlled by the business entity, indicating intrinsic characteristicsattributes, resources and/or capabilities.

In this context, the present study focuses on Greece and presents preliminary findings of a quantitative assessment on barriers to SMEs resilience to EWEs and contributes to an emerging body of literature aiming to respond to questions such as: i) How can SMEs be better prepared and more resilient to addressing challenges of CC?, and, ii) how can SMEs overcome barriers and enhance enabling conditions for increased resilience to EWEs? Responding to such pressing issues offers a discerning approach for addressing key aspects of sustainable development since equipping these companies to confront the climatic turbulence and extreme weather improves the development options of future generations (Sheffi, 2007; Moore and Manring, 2009; Denton et al., 2014). The study's originality stems from its contribution to the emerging field of climate services and the considerably under-researched topic of SMEs resilience to CC and environmental perturbations (Jones and Phillips, 2016). Empirical evidence on the business response $\mathrm{CC}$ impacts primarily focus on efforts to manage the carbon footprint of business entities (Okereke, 2007) while empirical findings on business CC adaptation is still thin on the ground, pertaining mostly to responsible corporate adaptation (e.g. Frey et al., 2015). With this in mind, the present study is the first in its field to provide a realistic examination of barriers SMEs facing in coping with EWEs.

The next section encapsulates the study's motivation and outlines a prior literature on SMEs and resilience to EWEs. The subsequent two sections present the materialmethods of the study and the main findings, respectively. A discussion of the results, along with implications for researcher, practitioners and policymakers, are presented in the final section. 


\section{Background and motivation for the study}

SMEs account for $99 \%$ of all European enterprises, they contribute to more than $50 \%$ of the total value added created by the EU business sector and drive employment by providing more than $60 \%$ of the private sector jobs (European Commission, 2015). In the case of Greece, $86.5 \%$ of total private sector employment is concentrated in these enterprises and account for $72.8 \%$ of gross value added. Balios et al. (2016) point out the country's critical characteristics that make it a unique opportunity for research on small business resilience. It is a developed economy and member of a community of developed countries in terms of macroeconomic and institutional structures. According to Eurostat, SMEs represent the absolute majority of domestic business activity (99.9\%) with considerably high employment growth (4.3\%) compared to the EU28 average (1.5\%), thus, retain a vital role in national growth in comparison to other EU28 countries. Lastly, Greece has been hit most severely from the recent economic crisis with more than seven years since the national economic downturn erupted. Indeed, 2015 data reveal that while value added growth at the Member State level was generally positive (EU28: 5.7\%), Greece experienced a 1\% decline in (Muller et al., 2016).

SMEs are more vulnerable and ill-prepared to face extreme weather conditions compared to their larger counterparts, so they are disproportionately affected by EWEs (Crichton, 2009). This is due to limited resources, and a tendency towards short-term planning, reacting to circumstances as they arise and focussing on survival (Smith and Smith, 2007). Likewise, they share less formalised structures and codified policies while they are most usually owner-managed resulting in a command-and-control management culture (Ates et al., 2013). These characteristics result in SMEs having limited opportunities to recover from adverse weather extremes or quickly turnaround their operation from a loss making to a profit making one (Ingirige and Wedawatta, 2011).

EWEs can disrupt the efficiency of supply chain networks where many SMEs are embedded and incur infrastructure and facility damages as well as inventory cost and downtime losses (Snyder and Shen, 2006). Considering that they play a major role in business-to-business markets and a large number of SMEs is embedded in large-scale production chains, increasing their resilience capacity to EWEs represents a matter that warrants considerable attention. This is also because these enterprises are strongly embedded in their local community (Spence, 2007). Therefore, they can play a pivotal role in mobilizing society to adopt anticipatory adjustments to the physical impacts of 
CC (Linnenluecke et al., 2013) and act as a useful stakeholder in relief and disaster recovery (Johnson et al., 2011). Hence, SMEs can contribute to the swift and successful recovery of local communities in which they are established (McManus et al., 2008), while the collective loss of a considerable number of SMEs due to weather extremes may devastate a local economy (Yoshida and Deyle, 2005).

Taking into account that EWEs-related economic damages have reached recordlevels over the past decade (Munich Re, 2013), addressing the barriers SMEs face in building their resilience capacity becomes a sheer necessity. Nevertheless, current literature on business responses to climate change stimuli (e.g. Linneluecke and Griffiths, 2010) is mostly fuelled by normative arguments on how organizational resilience can be developed while empirical findings on measurement and appraisal of organizational resilience to climate change are thin on the ground (Gasbarro and Pinske, 2016). Indeed, despite the fact that small and medium business entities potentially face greater losses from the effects of CC and EWEs (Runyan, 2006) and their role within supply chains and local sustainability is vital (Hong and Jeong, 2006), the organizational literature seldom concentrates on SMEs' resilience potential to such risks, with the exception of very few studies (Darnhofer, 2010; Wedawatta et al., 2010; Wedawatta and Ingirige, 2012; Kuruppu et al., 2013; Williams and Shaefer, 2013; Galbreath, 2014).

\section{Material and methods}

Our assessment seeks to identify associations between the various observed items forming the individual internal and external latent constructs as well as the associations between these constructs with the more general concepts of internal and external barriers in a holistic manner. To achieve this, we utilize recently-collected data (from an ongoing research project) gathered through structured questionnaires administered to owners-managers of SMEs located in the Attica prefecture, Greece $(n=109)$. The survey is conducted in municipalities of the greater urban area of Attica recently experiencing EWEs (i.e. heavy precipitation/storms, flash flooding or temperature extremes) and follows a two-stage sampling approach. In the first stage, 15 urban area blocks are selected based on the severity of EWE impacts on local business activities while in the second stage a snowball technique was followed to select those SMEs mostly affected from EWE in previous years. Among the 109 participating SMEs, 77 (71\%) pertain to 
retail/service sectors, while $32(29 \%)$ are enterprises with manufacturing/secondary sector activities. Table 1 presents sample size figures according to the number of employees per enterprise.

\section{(Insert Table 1 around here)}

The data collection instrument relies on 25 items measuring the level of agreement over a series of internal and external barriers (observed items) to resilience to EWEs, measured on a 1-5 Likert scale. A full description of the observed variables used as an initial input for constructing the latent factors described above can be found in Appendix 1.

To test the proposed methodological framework (Figure 1) we have followed a statistical modeling view. Specifically, we have fitted a structural equation model (SEM) (Bollen, 1989) in order to test the hypothesized conceptual model. The hypothesized modeling scheme is a 2-level conceptual model. We first explore the direct connections between the observed items forming the individual internal/external barriers and the corresponding constructs, whereas at the second layer of the model we add a testing of the two-layer SEM model, by allowing for the individual latent factors of internal and external barriers to directly affect the two general latter structures of internal and external barriers.

Selection of SEM modeling for the current analysis was deemed as a suitable statistical methodological approach (in comparison to more conventional approaches such as regression analysis) for various reasons. First, SEM differs from a typical regression-based model since with SEM the dependent and independent variables can be either observed or latent, a feature which cannot be addressed by typical regression analyses. Hence, SEM possesses a distinctive characteristic of latent variables being regressed on other latent variables, such as those analyzed in the current study. Second, structural equation modeling allows fitting model structures of different layers. The researcher can add connections not only between dependent (i.e. concepts of internal/external barriers) and explanatory variables but also between the explanatory ones (i.e. observed individual items and sub-constructs) so that indirect associations between the independent variables can be identified a feature that could not be implemented by typical regression techniques. 
In order to test the influence of the 25 items on the latent constructs that contribute to the SMEs' barriers, we performed the SEM model analysis using the AMOS software (Arbuckle, 2006) which allowed us to draw indicative findings from the sample of 109 SMEs. The sample size meets the absolute minimum requirement of 50 respondents for the SEM modeling to provide valid inferences (Hair et al., 2006), although the recommended size is 100 or above.

\section{Items utilized for the SEM modeling}

An analytical description of the observed items from the questionnaire that were utilized for the construction of the individual latent factors of internal/external barriers is provided in Table 1. In particular, a total number of 25 observed variables were selected - measured in an ordinal Likert scale - which was included into four factors to form the more general factors of internal and the external barriers, respectively. Analytically, the 8 individual factors utilized for the current analysis are described below, along with the Cronbach's $\alpha$ values (Bollen, 1989) and the percentage of variance of the selected items explained by each of the latent factors:

\section{Internal barriers}

1. 3-item scale factor (Cronbach's $\alpha: 0.809 ; \%$ of explained variance: 72.4) measuring barriers referring to the availability of Resources.

2. 3-item scale factor (Cronbach's $\alpha$ : 0.458 ; \% of explained variance: 49.63 ) measuring Understanding and Perception barriers.

3. 3-item scale factor (Cronbach's $\alpha: 0.66 ; \%$ of explained variance: 72.18) measuring barriers to the Implementation of resilience measures.

4. 3-item scale factor (Cronbach's $\alpha$ : 0.097; \% of explained variance: 36.01 ) measuring barriers pertaining to Attitudes and organizational culture.

\section{External barriers}

1. 3-item scale factor (Cronbach's $\alpha: 0.351 ; \%$ of explained variance: 43.6) measuring barriers to seeking for Business continuity/adaptation consulting services.

2. 3-item scale factor (Cronbach's $\alpha$ : $0.157 ; \%$ of explained variance: 39.22 ) measuring barriers of (macro-)Economic/market nature. 
3. 3-item scale factor (Cronbach's $\alpha$ : 0.553 ; \% of explained variance: 53.17) measuring barriers referring to Institutional conditions.

4. 4-item scale factor (Cronbach's $\alpha$ : 0.385 ; \% of explained variance: 64.64 ) measuring barriers relating to Support and guidance.

\section{(Insert Figure 1 around here)}

\section{Results}

The path diagram obtained by the fit of the SEM model is presented in the following Figure 2, summarizing the most important findings. The single-headed arrows in the path diagram are used to denote the direction of assumed causal influence while the numerical values next to each arrow indicate the (standardized) regression weights $(\beta$ 's) of the corresponding item on the latent variables as well as the weights from the four internal/external groups of barriers to the overall factors of external and internal barriers. The statistical significance of each association is indicated in the graph with the use of asterisks. The loadings of non-statistically significant paths are not reported for space saving, yet, the corresponding arrow of causality is marked with a dashed line in the case of the associations found to be non-significant.

The results of the analysis revealed that the specific model conceptualization provides a moderate to good fit to the data. Fit statistics for the SEM model reveal that the path analysis structure tested provided a moderate to good fit, since that most of the values are at the borderlines of acceptable limits.

Most of the observed items of internal barriers to SMEs' resilience to EWEs (questionnaire items Q1 to Q12) have a significant effect on the assigned corresponding factor, with the exception of the 'Attitudes and organizational culture' internal barrier. The most dominant factors are found to be those of 'Resources' (regression weight $\beta$ : 0.999; p-value<0.001) and 'Understanding and perception' barriers ( $\beta$ : 0.72 ; pvalue $<0.001)$. A marginal significance is also observed for the 'Implementation' barriers factor $(\beta$ : 0.355; $\mathrm{p}$-value $<0.001)$.

As regards to the external barriers, the most important barrier factors are those of resilience barriers referring to 'Institutional conditions' $(\beta$ : 0.791 ; p-value<0.001) and 'Support and guidance' ( $\beta$ : 0.999; p-value<0.001). The 'Economic' barriers are 
contributing marginally to the external barriers construct $(\beta: 0.556$; $p$-value $<0.1)$. It is only the effects of the factor pertaining to the provision of business continuity/adaptation consulting services that is found to be non-significant for the external barriers.

The importance of how the various observed variables contribute to the individual latent constructs of external and internal barriers was also respectively examined. As regards the 'Resources' barrier construct, it is observed that all three variables (i.e. [Q1], [Q2] and [Q3]) are of importance for its construction. This indicates that resilience due to the internal factor of resources is almost equally attributed to the lack of time to design, implement and monitor resilience measures, the lack of relevant training and expertise by staff members and due to financial constraints. This is also supported for the latent construct of the 'Understanding and perceptions' barrier, since all three tested items load strongly on the specific factor, with most dominant effects attributed to the perceived absence of clear benefits for the firm $(\beta$ : $0.682 ; \mathrm{p}$-value $<0.001)$ and to additional, potentially bureaucratic, operational procedures $(\beta$ : 0,682 ; p-value $<0.001)$. In contrast, the 'Implementation' barrier construct is primarily affected by the observed variable [Q7] reflecting a perceived interruption of more important operational processes within the firm $(\beta: 0.493$; $p$-value $<0.001)$, whereas it is marginally affected by variable [Q8], i.e. doubts on the actual effectiveness of resilience actions ( $\beta$ : $0.181 ; \mathrm{p}$ value $<0.1)$.

As regards to the items that comprise the important latent constructs of external barriers referring to 'Institutional conditions' and 'Support and guidance', it is observed that all individual observed items load strongly on the latter constructs. In particular, as regards the 'Institutional conditions' barrier we find that the complexities of the regulatory framework [Q21] is an important factor for this barrier type $(\beta: 0,623 ; \mathrm{p}$ value $<0.001$ ). Likewise, the lack of related promotion activities [Q19] and inadequate information provision by authorities on the design and implementation of such resilience measures [Q20] are found to have a strong positive effect on the 'Institutional conditions' barrier. The 'Support and guidance' barrier is mostly affected by the (perceived) low quality and inconsistency $(\beta$ : 0.71 ; p-value<0.001) as well as the lack of SME-specific knowledge $(\beta$ : 0.668; $\mathrm{p}$-value<0.001) characterizing external support mechanisms (i.e. [Q19] and [Q20]). Inadequate support of trade associations and business chambers $(\beta$ : 0.34 ; $p$-value $<0.05)$ along with absence of clear guidance from stakeholders $(\beta$ : 0.449; $p$-value<0.001) are also found to be critical aspects of EWEs 
resilience barriers. The economic-related barrier, which contributes marginally to the overall latent construct of external barriers, is mainly affected by the volatile macroeconomic environment variable [Q16] ( $\beta$ : 0.196; p-value<0.1).

Our SEM modeling tests failed to obtain a stable model convergence, by retaining the associations between the two general latent constructs of internal-external barriers with the fourth-layer factor of barriers to SMEs resilience (as hypothesized in Figure 1). While this is a task of ongoing research, this finding is indicative of the diversity between the internal and external barriers to building resilience as a complex concept and their differences with respect from the SMEs' owners-managers viewpoints and their related responses.

\section{(Insert Figure 2 around here)}

\section{Concluding remarks}

EWEs pose threats of massive discontinuous changes and reliance on existing organizational routines and business-as-usual approaches are deemed to be insufficient and bound to lead to suboptimal responses (Linnenluecke and Griffiths, 2010; Winn et al., 2011; Linnenluecke et al., 2012). A key issue in decision-making towards fostering business resilience to EWEs is to identify barriers that undermine the ability of firms to respond in a timely and effective manner to such environmental stimuli and disruptive events. The way SMEs respond to EWEs has yet to be thoroughly investigated in the literature (Linnenluecke et al., 2012; Winn and Pogutz, 2013). Thus, the study's results present a first indication that certain elements of external and internal barriers have a significant positive effect on SMEs resilience to EWEs while other hypothesized associations were not found to be important. Reliance on a single set of inhibitory factors may not allow the enhancement of organizational resilience if other clusters of barriers which can offset desirable outcomes are overlooked. Therefore, all barrier groups should be identified and considered and by devising relevant schemes and incentives under the scope of a 'climate-proof' SME sector. Internal barriers pertaining to resources as well as managerial perceptions can be critical as suggested by the statistical analysis of gathered data. In relation to the external barriers, those referring to institutional conditions and to mechanisms of external support and guidance are equally critical in defining resilience responses. However, the main outcome of the analysis is 
that the hypothesized model of SMEs' barriers can be a valid instrument for linking the various individual latent constructs of resilience barriers with the more generic concepts of internal and external inhibitory factors. In this respect, our study reveals that a better understanding of multiple parameters hindering SME actions to EWEs could yield a more refined explanation of how these enterprises interpret and handle such physical impacts. In line with prior evidence, the study indicates that resource constraints and managerial perceptions seem to be key parameters for the level of engagement in resilience measures (Williams and Schaefer, 2013; Galbreath, 2014). Likewise, external factors pertaining to institutional conditions-arrangements and stakeholder support have been point out in previous resilience studies (Dranhofer, 2010; Kuruppu et al., 2013).

Assessing barriers to resilience is indeed a promising avenue of fruitful evidence for policy interventions aimed at stimulating SMEs to upgrade their ability to withstand EWE phenomena. Findings from resilience studies such as ours can be useful in putting forth a tentative framework on determinants of SME response to climate risks, informing strategic SME management as well as regional or sectorial policy-design so as to steer these enterprises towards sustainability. The latter could be achieved by primarily focusing on industries facing high climate risks or particularly vulnerable to EWEs. Through the provision of ad hoc policy tools such as tax reliefs and subsidies, reward schemes, awareness-raising or capacity-building initiatives, the resilience capacity of these CC-sensitive SMEs could be strengthened and barriers reduced. Further, government support to market mechanisms in terms of fee-based and customized climate services for the production and communication of best available CC knowledge to small business entities could also be a strong determinant of effectively coping with climate-induced physical changes (European Commission, 2015b). Similar to market-based CC mitigative actions (e.g. emission trading schemes), policy-making on reducing the time-to-market of respective resilience innovations would promote a long-term adaptation trajectory for such enterprises.

Internal training and development programs could be a first step in assisting staff members to gain better apprehension of what EWE resilience encapsulates how it can be nurtured. In order to encourage SMEs being at early stages of the resilience learning curve, policies that stimulate multi-stakeholder partnerships for local resilience strategies as well as information- or expertise-sharing could play a critical role. This is because local stakeholders can potentially contribute to outreach activities for information-sharing, and the promotion of up-to-date resilience measures within the 
local community (including the local business sector). Therefore, in reducing SMEs barriers to EWEs resilience capacity, governmental bodies should work on cultivating local governance and utilize the dynamics of local jurisdiction in tackling the $\mathrm{CC}$ challenges (Gunawansa and Kua, 2014). By providing resilience-specific market intelligence, addressing knowledge gaps and disseminating best-practices guides, governmental bodies may assist in fostering the enabling environment for successful SMEs resilience. Indeed, policymakers should consider stimulating learning-based and participative stakeholder processes (Kemp et al., 2007) backed up with economic incentives to SMEs, since resilience measures may involve considerable investments as well as long-term payback periods (Galbreath, 2014). This could be further supported by initiating regional SME initiatives aiming to attract investment funding opportunities and facilitate inter-firm cooperation or synergies which could drive resilience-specific innovations and refined SME management capabilities. Strategic directions such as those set forth by the European Commission (2013; European Committee of the Regions, 2017) are an important step forward as they can navigate enterprises through CC complexities by increasing available resilience options, supporting mechanisms and 'rules of thumb' to counter EWEs pressures.

Beside these managerial and policy implications, certain avenues for future research emerge as well. Indeed, our assessment is location-specific and, thus, evidence cannot be generalized. However, it does indicate a need for more spatial research to account how and why SMEs under different regional peculiarities face difficulties and fail to cope with such environmental disruptions. In our analysis we focused on SMEs with prior experience of EWEs adverse impacts. This could be extended through a comparative lens to a wider range of enterprise profiles (not just those being previously acquainted with an EWE or most vulnerable to such disruptions) in order to shed light on the varying levels of preparedness and the related spectrum of resilience barriers. Likewise, the business activity context (i.e. sector) as well as SME owners' proenvironmental behaviour should be of major interest to resilience researchers. Longitudinal and action research studies are necessary to capture how barriers are reduced, resilience capacity is shaped in temporal terms and related strategies are implemented within the enterprise over time. Finally, a central and fruitful area for future research could be to contrast empirical evidence on SMEs resilience barriers with findings from inhibitory factors related to $\mathrm{CC}$ mitigation measures. Addressing both sides of the same coin can yield fruitful insights for the development of composite 
frameworks on the array of challenges SMEs face in coping with CC and provide the individual enterprise with a holistic perspective of relevant strategic pathways.

\section{References}

Amran A, Ooi SK, Wong CY, Hashim F. 2016. Business strategy for climate change: An ASEAN perspective. Corporate Social Responsibility and Environmental Management 23(4): 213-227.

Arbuckle JL. 2006. Amos 7.0 User's Guide. Chicago: SPSS.

Ates A, Garengo P, Cocca P, Bititci U. 2013. The development of SME managerial practice for effective performance management. Journal of Small Business and Enterprise Development 20(1): 28-54.

Balios D, Daskalakis N, Eriotis N, Vasiliou D. 2016. SMEs capital structure determinants during severe economic crisis: The case of Greece. Cogent Economics and Finance, 4(1): 1145535.

Barnett J. 2001. Adapting to climate change in Pacific Island countries: the problem of uncertainty. World Development 29(6): 977-993.

Bollen KA. 1989. Structural equations with latent variables. New York: WileyInterscience.

Chan E. 2008. Barriers to EMS in the hotel industry. Hospitality Management 27: 187196.

Crichton D. 2009. The Climate Change Report - Coping with climate change: risks and opportunities for Insurers. London: The Chartered Insurance Institute.

Darnhofer I. 2010. Strategies of family farms to strengthen their resilience. Environmental Policy and Governance 20(4): 212-222.

Denton F, Wilbanks TJ, Abeysinghe AC, Burton I, Gao Q, Lemos MC, Masui T, O'Brien KL, Warner K. 2014.: Climate-resilient pathways: adaptation, mitigation, and sustainable development. In: Climate Change 2014: Impacts, Adaptation, and Vulnerability. Part A: Global and Sectoral Aspects. Contribution of Working Group II to the Fifth Assessment Report of the Intergovernmental Panel on Climate Change, Field CB, et al. (eds). Cambridge: Cambridge University Press, 1101-1131.

Dlugolecki A. 2009. Coping with Climate Change: Risks and Opportunities for Insurers. London: The Chartered Insurance Institute.

European Commission 2012. The EU approach to resilience: Learning from food security crises. Brussels: European Commission.

European Commission. 2013. An EU Strategy on Adaptation to Climate Change. : COM(2013)216, Brussels: European Commission.

European Commission. 2015a. Annual Report on European SMEs 2014/2015. Brussels: European Commission.

European Commission. 2015b. A European research and innovation roadmap for climate services. Brussels: DG Research and Innovation. 
European Committee of the Regions. 2017. Opinion of the European Committee of the Regions: Towards a new EU climate change adaptation strategy - taking an integrated approach. Luxembourg: Publications Office of the European Union.

Evangelinos K, Nikolaou I, Leal Filho W. 2015. The effects of climate change policy on the business community: A corporate environmental accounting perspective. Corporate Social Responsibility and Environmental Management 22(5): 257-270.

Forzieri G, et al. 2016 Multi-hazard assessment in Europe under climate change. Climatic Change, doi: 10.1007/s10584-016-1661-x.

Frey B, et al. 2015. The Business Case for Responsible Corporate Adaptation: Strengthening Private Sector and Community Resilience.: A Caring for Climate Report. UN Global Compact.

Galbreath J. 2014. Climate change response: Evidence from the Margaret River wine region of Australia. Business Strategy and the Environment 23(2): 89-104.

Gasbarro F, Pinkse J. 2016. Corporate adaptation behaviour to deal with climate change: the influence of firm-specific interpretations of physical climate impacts. Corporate Social Responsibility and Environmental Management 23(3): 179-192.

Gasbarro F, Rizzi F, Frey M. 2016. Adaptation measures of energy and utility companies to cope with water scarcity induced by climate change. Business Strategy and the Environment 25(1): 54-72.

Gunawansa A, Kua HW. 2014. A comparison of climate change mitigation and adaptation strategies for the construction industries of three coastal territories. Sustainable Development 22(1): 52-62.

Halkos G, Skouloudis A. 2016. Exploring the current status and key determinants of corporate disclosure on climate change: Evidence from the Greek business sector. Environmental Science and Policy 56: 22-31.

Hair JF, Black WC, Babin BJ, Anderson RE, Tatham LR. 2006. Multivariant Data Analysis. New Jersey: Pearson International Edition.

Hillary R. 2004. Environmental management systems and the smaller enterprise. Journal of Cleaner Production, 12, 561-569.

Hong P, Jeong J. 2006. Supply chain management practices of SMEs: From a business growth perspective. Journal of Enterprise Information Management 19(3): 292-302.

Ingirige B, Wedawatta G. 2011. SME Resilience to Extreme Weather Events: Important initiatives for informing policy making in the area. International Conference on Building Resilience, Sri Lanka.

Intergovernmental Panel on Climate Change (IPCC). 2013. Fifth Assessment report. Cambridge University Press.

Johnson BR, Connolly E, Carter TS. 2011. Corporate social responsibility: The role of fortune 100 companies in domestic and international natural disasters. Corporate Social Responsibility and Environmental Management 18(6): 352-369.

Jones AW, Phillips A. 2016. Voluntary business engagement in climate change: A study of the ClimateWise principles. Journal of Cleaner Production 137: 131-143.

Kemp R, Loorbach D, Rotmans J. 2007. Transition management as a model for managing processes of co-evolution towards sustainable development. International Journal of Sustainable Development and World Ecology 14: 78-91. 
Korhonen J, Seager TP. 2008. Beyond eco-efficiency: A resilience perspective. Business Strategy and the Environment 17(7): 411-419.

Kuruppu N, Murta J, Mukheibir P, Chong J, Brennan T. 2013. Understanding the adaptive capacity of Australian small-to-medium enterprises to climate change and variability. Gold Coast: National Climate Change Adaptation Research Facility (NCCARF).

Lengnick-Hall CA, Beck TE, Lengnick-Hall ML. 2011. Developing a capacity for organizational resilience through strategic human resource management. Human Resource Management Review 21(3): 243-255.

Linnenluecke M, Griffiths A. 2010. Beyond adaptation: resilience for business in light of climate change and weather extremes. Business and Society 49(3): 477-511.

Linnenluecke MK, Stathakis A, Griffiths A. 2011. Firm relocation as adaptive response to climate change and weather extremes. Global Environmental Change 21(1): 123133.

Linnenluecke MK, Griffiths A, Winn M. 2012. Extreme weather events and the critical importance of anticipatory adaptation and organizational resilience in responding to impacts. Business Strategy and the Environment 21(1): 17-32.

Linnenluecke MK, Griffiths A, Winn M. 2013. Firm and industry adaptation to climate change: a review of climate adaptation studies in the business and management field. Wiley Interdisciplinary Reviews: Climate Change 4(5): 397-416.

McManus S, Seville E, Vargo J, Brunsdon D. 2008. Facilitated process for improving organizational resilience. Natural Hazards Review 9(2): 81-90.

Moore SB, Manring SL. 2009. Strategy development in small and medium sized enterprises for sustainability and increased value creation. Journal of Cleaner Production 17(2): 276-282.

Muller P, Devnani S, Julius J, Gagliardi D, Marzoc C. 2016. Annual Report on European SMEs 2015/2016: SME recovery continues. European Union, contract number: EASME/COSME/2015/012.

Munich Re. 2013. 2012 Natural Catastrophe Year in Review. Munich: Munich Re.

Okereke C. 2007. An exploration of motivations, drivers and barriers to carbon management: the UK FTSE 100. European Management Journal 25: 475-486.

Okereke C, Wittneben B, Bowen F. 2012. Climate change: Challenging business, transforming politics. Business and Society 51(1): 7-30.

Poumadere M, Mays C, Le Mer S, Blong R. 2005. The 2003 heat wave in France: dangerous climate change here and now. Risk Analysis 25(6): 1483-1494.

Runyan RC. 2006. Small business in the face of crisis: identifying barriers to recovery from a Natural Disaster. Journal of Contingencies and Crisis Management 14(1): 1226.

Seville E, Brunsdon D, Dantas A, Le Masurier J, Wilkinson S, Vargo J. 2008. Organisational resilience: Researching the reality of New Zealand organisations. Journal of Business Continuity and Emergency Planning 2(3): 258-266.

Sheffi Y. 2007. The resilient enterprise: overcoming vulnerability for competitive advantage. MIT Press. 
Shi H, Peng SZ, Liu Y, Zhong P. 2008. Barriers to the implementation of cleaner production in Chinese SMEs: government, industry and expert stakeholders' perspectives. Journal of Cleaner Production 16: 842-852.

Smith MH, Smith D. 2007. Implementing strategically aligned performance measurement in small firms. International Journal of Production Economics 106(2): 393-408.

Snyder LV, Shen ZJM. 2006. Supply chain management under the threat of disruptions. The Bridge 36, 39-45.

SPSS Inc. 1999. SPSS Base 10.0 for Windows User's Guide. Chicago: SPSS Inc.

Spence LJ. 2007. CSR and small business in a European policy context: the five "C" $\mathrm{s}$ of CSR and small business research agenda. Business and Society Review 112(4): 533-552.

Stern NH. 2007. The economics of climate change: The Stern review. Cambridge University Press.

Sutcliffe KM, Vogus TJ. 2003. Organizing for Resilience. Positive Organizational Scholarship: Foundations of a New Discipline. KS Cameron, JE Dutton, RE Quinn. San Francisco: Berrett-Koehler, 94-110.

Tsalis TA, Nikolaou IE. 2017. Assessing the effects of climate change regulations on the business community: a system dynamic approach. Business Strategy and the Environment, doi: 10.1002/bse.1953.

Wedawatta G, Ingirige B, Amaratunga D. 2010. Building up resilienc e of construction sector SMEs and their supply chains to extreme weather events. International Journal of Strategic Property Management 14(4): 362-375.

Wedawatta G, Ingirige B. 2012. Resilience and adaptation of small and medium-sized enterprises to flood risk. Disaster Prevention and Management: An International Journal 21(4): 474-488.

Weick K, Sutcliffe K. 2001. Managing the unexpected: Assuring high performance in an age of uncertainty. Wiley: San Francisco.

Weinhofer G, Busch T. 2013. Corporate strategies for managing climate risks. Business Strategy and the Environment 22(2): 121-144.

Whiteman G, de Vos DR, Chapin FS, Yli-Pelkonen V, Niemelä J, Forbes BC. 2011. Business strategies and the transition to low-carbon cities. Business Strategy and the Environment 20(4): 251-265.

Williams S, Schaefer A. 2013. Small and medium-sized enterprises and sustainability: Managers' values and engagement with environmental and climate change issues. Business Strategy and the Environment 22(3): 173-186.

Winn M, Kirchgeorg M, Griffiths A, Linnenluecke MK, Günther E. 2011. Impacts from climate change on organizations: a conceptual foundation. Business Strategy and the Environment 20(3): 157-173.

Winn MI, Pogutz S. 2013. Business, ecosystems, and biodiversity: new horizons for management research. Organization and Environment 26(2): 203-229.

Yoshida K, Deyle RE. 2005. Determinants of small business hazard mitigation. Natural Hazards Review 6(1): 1-12. 


\begin{tabular}{|c|c|c|c|c|c|c|}
\hline \multicolumn{7}{|c|}{ Please indicate your level of agreement with the following statements: } \\
\hline $\mathbf{n} / \mathbf{n}$ & $\begin{array}{l}\text { A critical inhibitory factor in building the resilience of } \mathrm{my} \\
\text { enterprise towards extreme weather events is: }\end{array}$ & $\begin{array}{l}\text { Strongly } \\
\text { disagree }\end{array}$ & Disagree & Neutral & Agree & $\begin{array}{c}\text { Strongly } \\
\text { agree }\end{array}$ \\
\hline Q1 & $\begin{array}{l}\text { Lack of time to design, implement and monitor such resilience } \\
\text { measures }\end{array}$ & $\mathrm{o}$ & $\mathrm{o}$ & $\mathrm{O}$ & o & $\mathrm{O}$ \\
\hline Q2 & Lack of relevant training and expertise by members of the staff & $\mathrm{O}$ & $\mathrm{O}$ & $\mathrm{O}$ & $\mathrm{O}$ & $\mathrm{O}$ \\
\hline Q3 & Financial constraints & $\mathrm{O}$ & $\mathrm{O}$ & $\mathrm{O}$ & $\mathrm{O}$ & $\mathrm{O}$ \\
\hline Q4 & Absence of clear benefits for the firm & o & o & o & o & $\mathrm{O}$ \\
\hline Q5 & The relevant management cost is high & $\mathrm{O}$ & $\mathrm{O}$ & $\mathrm{O}$ & $\mathrm{O}$ & $\mathrm{O}$ \\
\hline Q6 & It incurs additional, bureaucratic, internal procedures & o & o & o & o & $\mathrm{O}$ \\
\hline Q7 & $\begin{array}{l}\text { It may interrupt other (important) operational processes within the } \\
\text { firm }\end{array}$ & $\mathrm{O}$ & o & $\mathrm{o}$ & o & o \\
\hline Q8 & Doubts about the effectiveness of such actions and their objectives & $\mathrm{O}$ & $\mathrm{O}$ & $\mathrm{O}$ & $\mathrm{O}$ & $\mathrm{O}$ \\
\hline Q9 & $\begin{array}{l}\text { Difficulties in evaluating comprehensively related environmental } \\
\text { risks }\end{array}$ & $\mathrm{o}$ & o & $\mathrm{O}$ & o & $\mathrm{O}$ \\
\hline Q10 & $\begin{array}{l}\text { Previous experience with nonfinancial management systems proved } \\
\text { they are inefficient within my enterprise }\end{array}$ & $\mathrm{o}$ & o & $\mathrm{o}$ & $\mathrm{o}$ & $\mathrm{O}$ \\
\hline Q11 & $\begin{array}{l}\text { They may bring forward drastic and unwanted changes to my } \\
\text { enterprise }\end{array}$ & $\mathrm{o}$ & o & $\mathrm{o}$ & $\mathrm{O}$ & $\mathrm{O}$ \\
\hline Q12 & I have more critical-important issues to engage with & $\mathrm{O}$ & $\mathrm{O}$ & $\mathrm{O}$ & $\mathrm{O}$ & $\mathrm{O}$ \\
\hline Q13 & The costs of consulting on business continuity planning is high & $\mathrm{O}$ & $\mathrm{O}$ & $\mathrm{O}$ & o & $\mathrm{O}$ \\
\hline Q14 & $\begin{array}{l}\text { Business continuity consultants serve their intrinsic interests which } \\
\text { exceed their role in improving business operation and performance }\end{array}$ & $\mathrm{O}$ & o & $\mathrm{o}$ & $\mathrm{o}$ & $\mathrm{o}$ \\
\hline Q15 & $\begin{array}{l}\text { Business continuity consultants will offer low quality as well as } \\
\text { largely prescriptive and/or bureaucratic services to the firm }\end{array}$ & $\mathrm{O}$ & o & $\mathrm{o}$ & $\mathrm{o}$ & $\mathrm{o}$ \\
\hline Q16 & $\begin{array}{l}\text { The volatile economic environment influences the importance } \\
\text { attached to resilience measures against EWEs }\end{array}$ & $\mathrm{O}$ & o & $\mathrm{O}$ & $\mathrm{O}$ & $\mathrm{O}$ \\
\hline Q17 & $\begin{array}{l}\text { There are no economic incentives to motivate engagement in } \\
\text { resilience measures }\end{array}$ & $\mathrm{O}$ & $\mathrm{O}$ & $\mathrm{o}$ & $\mathrm{o}$ & $\mathrm{o}$ \\
\hline Q18 & $\begin{array}{l}\text { The implementation of resilience measures to EWEs has no value in } \\
\text { the market place my enterprise operates in }\end{array}$ & $\mathrm{o}$ & o & $\mathrm{o}$ & $\mathrm{o}$ & $\mathrm{o}$ \\
\hline Q19 & $\begin{array}{l}\text { Lack of related promotion activities by apposite governmental } \\
\text { bodies }\end{array}$ & $\mathrm{O}$ & $\mathrm{o}$ & $\mathrm{o}$ & o & $\mathrm{O}$ \\
\hline Q20 & $\begin{array}{l}\text { Inadequate information provision by the authorities on the design } \\
\text { and implementation of resilience measures to EWEs }\end{array}$ & o & $\mathrm{o}$ & $\mathrm{o}$ & $\mathrm{o}$ & $\mathrm{o}$ \\
\hline Q21 & $\begin{array}{l}\text { The regulatory framework is complex and strict and undermines any } \\
\text { attempts to endorse resilience-related modifications within the } \\
\text { enterprise }\end{array}$ & $\mathrm{o}$ & $\mathrm{o}$ & o & $\mathrm{o}$ & $\mathrm{o}$ \\
\hline Q22 & Mechanisms of external support are of low quality and inconsistent & $\mathrm{O}$ & $\mathrm{O}$ & $\mathrm{O}$ & $\mathrm{O}$ & $\mathrm{O}$ \\
\hline Q23 & $\begin{array}{l}\text { Mechanisms of external support lack knowledge of the intrinsic } \\
\text { characteristics of the sector my enterprise operates in }\end{array}$ & o & o & $\mathrm{O}$ & $\mathrm{O}$ & $\mathrm{O}$ \\
\hline Q24 & $\begin{array}{l}\text { The trade associations/business chambers my enterprise pertains to } \\
\text { offer inadequate support to resilience enhancement }\end{array}$ & $\mathrm{O}$ & o & $\mathrm{O}$ & o & $\mathrm{O}$ \\
\hline Q25 & $\begin{array}{l}\text { Absence of clear guidance, information provision to increase } \\
\text { awareness as well as assistance by other primary stakeholders of the } \\
\text { firm on how to enhance resilience to EWEs }\end{array}$ & $\mathrm{O}$ & $\mathrm{O}$ & $\mathrm{O}$ & $\mathrm{O}$ & $\mathrm{O}$ \\
\hline
\end{tabular}


Table 1. Sample size per enterprise category

\begin{tabular}{|c|c|}
\hline $\begin{array}{c}\text { Enterprise category } \\
\text { (staff headcount) }\end{array}$ & $\begin{array}{c}\text { Number of } \\
\text { enterprises }(\%)\end{array}$ \\
\hline Medium-sized $(<250)$ & $15(14 \%)$ \\
\hline Small $(<50)$ & $50(46 \%)$ \\
\hline Micro $(<10)$ & $44(40 \%)$ \\
\hline
\end{tabular}

Figure 1. The proposed methodological framework

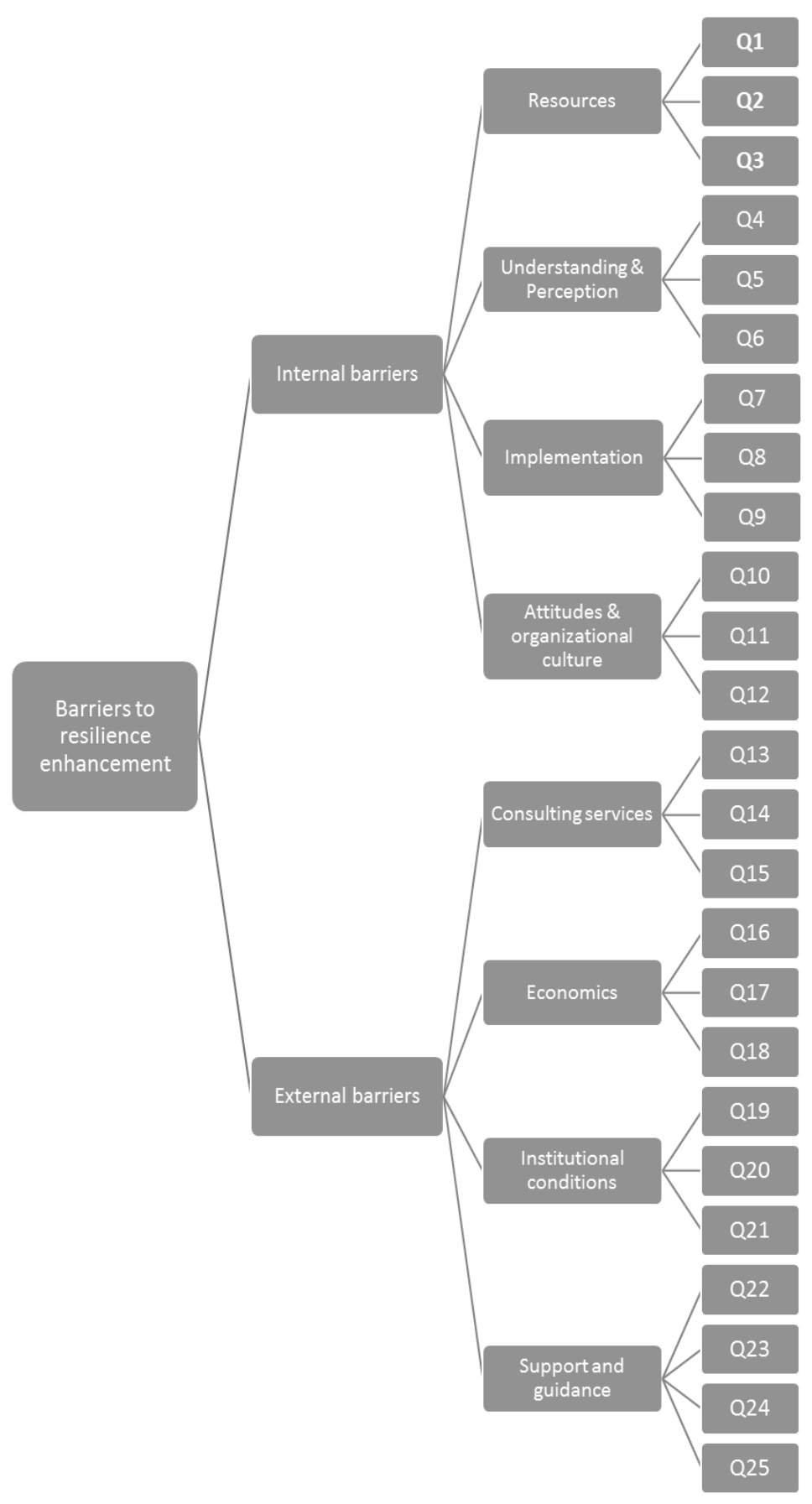




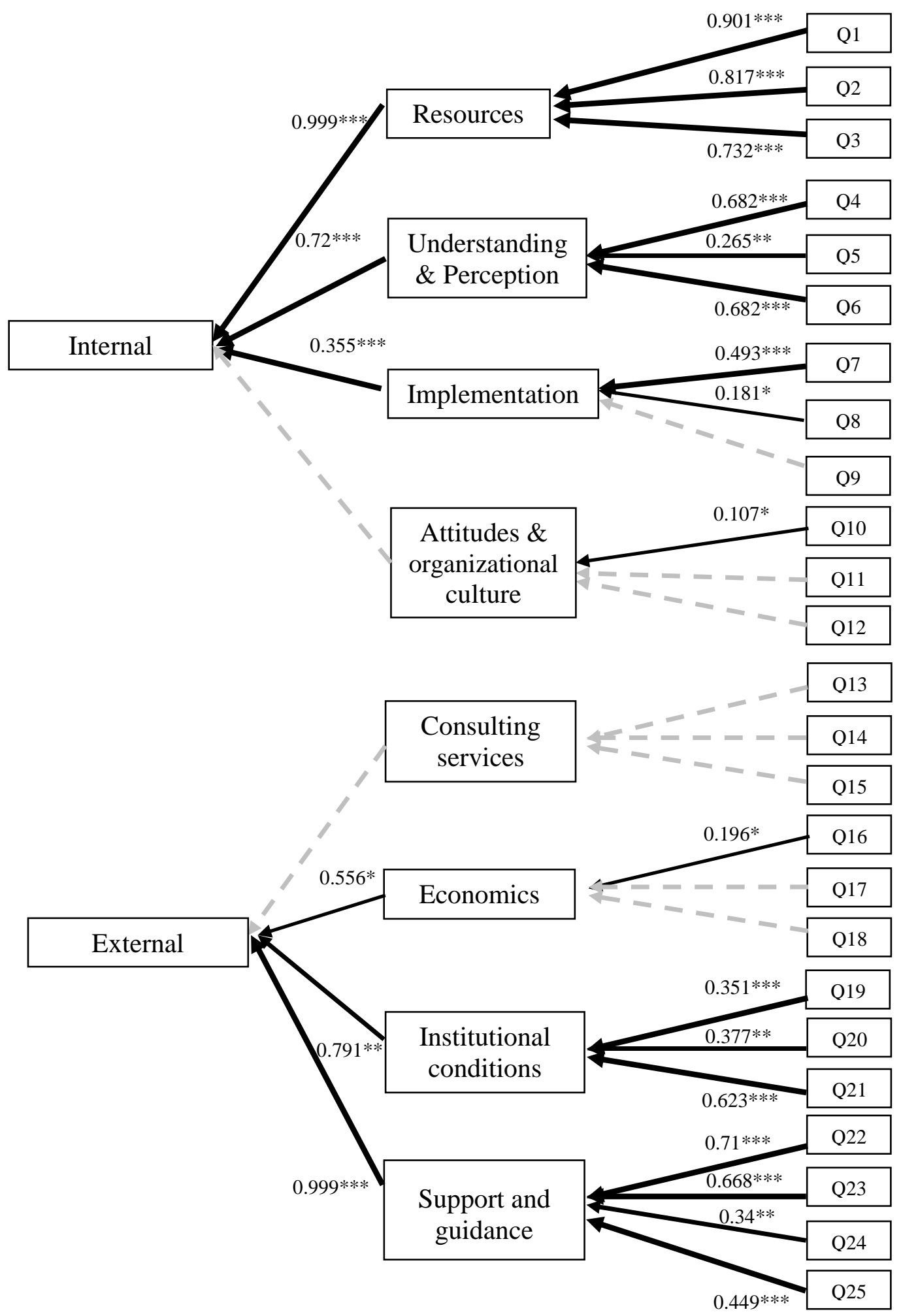

$\longrightarrow$ Significant direct positive effect Insignificant direct effect

$*: \mathrm{p}<0.1 ; * * \mathrm{p}<0.05$; Chi-square: 310.958 (p-value: 0.05); GFI: 0.77; AGFI: 0.728. 